\title{
Owner of Towing Company Dies When Struck by Driver of a Box Truck
}

\section{Incident Number: 12KY035}

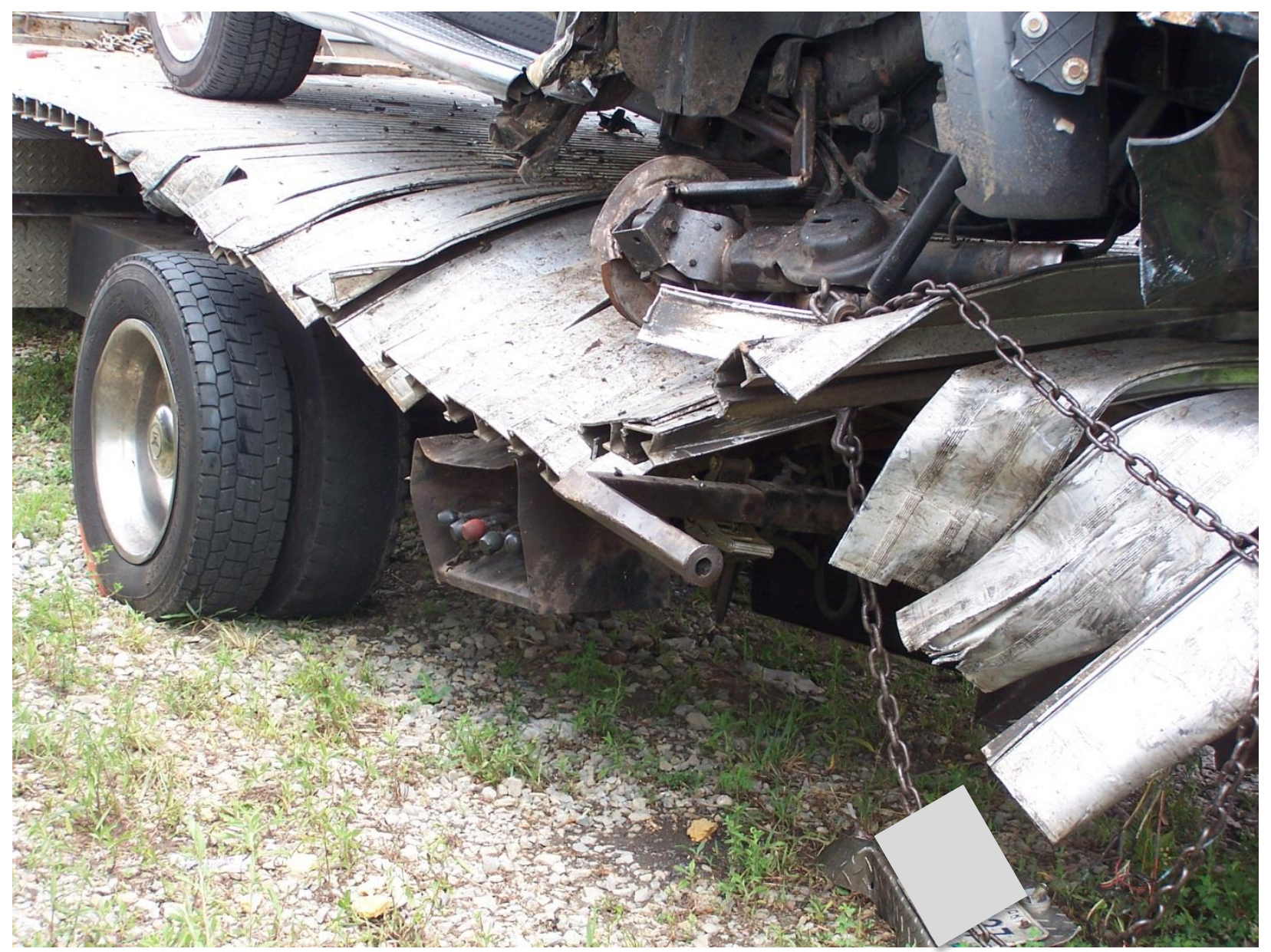

The tow truck struck by the box truck. Photos included in this report are property of Kentucky FACE.

Kentucky Fatality Assessment and Control Evaluation Program Kentucky Injury Prevention and Research Center 333 Waller Avenue

Suite 242

Lexington, Kentucky 40504

Phone: 859-323-2981

Fax: 859-257-3909

www.kiprc.uky.edu

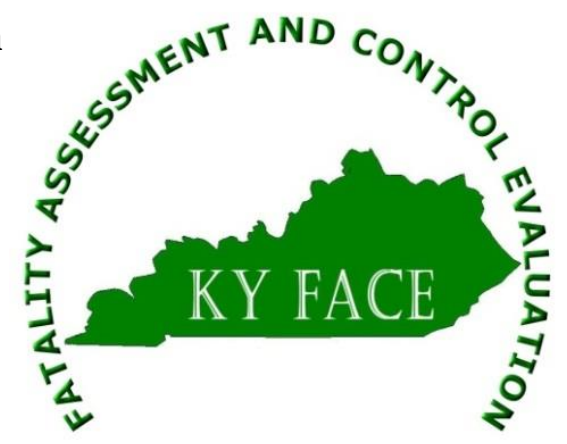




\title{
Kentucky Fatality Assessment and Control Evaluation (FACE) Program Incident Number: 12KY035 \\ Release Date: 2014 \\ Subject: Owner of Towing Company Dies When Struck by Driver of a Box Truck
}

\begin{abstract}
Summary
In the early morning hours of a summer day, a 49-year-old male owner-operator of a towing company died when he was struck by a driver operating a box truck. The towing company had been called to retrieve a sport utility vehicle (SUV) that had broken down in another state and was returning the vehicle to its owner in Kentucky. It was approximately 4:00 a.m. when the towing company owner and his two sons (ages 2 and 18) were on an interstate returning with the SUV, when the operator thought the load felt strange. He parked his tow truck on the right hand shoulder and was standing on the driver's side at the rear of the trailer checking the load's securement, when a box truck in the right lane, driven by a 24 -year-old male, struck him. The tow truck driver's 18-year-old son called emergency medical services to the scene. They arrived, followed by the coroner who declared the towing operator dead at the scene. The driver of the box truck was arrested and subsequently charged with murder, driving under the influence (.115 BAC), driving without insurance, and in violation of numerous other commercial vehicle regulations.
\end{abstract}

To prevent future occurrences of similar incidents, the following recommendations have been made:

Recommendation No. 1: Four points of securement should be used when transporting a load.*

Recommendation No. 2: Towing operators should receive refresher safety and operational training annually.

Recommendation No. 3: The maximum carrying capacity of the tow truck should not be exceeded.

Recommendation No. 4: Portable warning devices should be used when outside of the truck to alert approaching motorists.

Recommendation No. 5: Appropriate high-visibility vests should be worn by persons working along highways and streets.

Recommendation No. 6: There should be increased public awareness of the "Move Over Law" in Kentucky. 


\title{
Recommendation No. 7: A proper pre-trip and post-trip inspection should be performed at the beginning and closing of each day.
}

\author{
Recommendation No. 8: Whenever possible, the tow truck driver should pull over at a \\ 'safe' location that allows the truck to be out of the way of approaching traffic.
}

\section{Background}

The towing company involved in this incident provided roadside assistance and towing services. The company maintained three tow trucks, employed three operators, and went out of business after this incident occurred.

The box truck involved in this incident was owned and operated by one man, the 24-year-old driver in the incident, who used it to transport produce locally. He also used the box truck to attend auctions and acquire items for sale.

The temperature on the day of the incident ranged from 71 degrees Fahrenheit to 99 degrees Fahrenheit. There was no precipitation.

\section{Investigation}

The Kentucky Fatality Assessment and Control Evaluation Program was notified of an occupational fatality involving a tow truck operator and a box truck on an interstate. A site visit was made and photographs were taken. Interviews were conducted with the responding towing company and police.

On a summer day, a towing company was contacted to retrieve a sport utility vehicle whose owner was traveling from Kentucky to South Carolina, when the SUV became disabled. The SUV was approximately 225 miles away from the towing company's yard.

To retrieve the vehicle, the owner of the towing company and his two sons, ages 2 and 18, settled into one of the company's three tow trucks and began the 225 mile route that would take approximately $3 \frac{1}{2}$ hours. The tow truck was a 2000 model equipped with a rollback trailer, and had a gross vehicle weight of 17,500 pounds. As they drove south on the interstate, the 2-yearold was in a car seat located in the middle of the front seat of the truck. The owner, a 49-yearold male, drove while his 18-year-old son rode next to the passenger door.

Upon arriving at their destination, the SUV was loaded onto the rollback using three anchoring points. The tow truck operator engaged the vehicle warning lights and he and his two sons headed north toward home, 225 miles away, and another $3 \frac{1 / 2}{2}$ hours. 
After traveling approximately 1 1/2 hours and 90 miles, the tow truck operator thought the load felt different. He asked his oldest son if he heard anything odd, to which his son replied that yes, he thought he had. It was just before 4:00 a.m. and the father pulled the tow truck over to the right shoulder of the interstate next to a guardrail. He exited the cab and proceeded to the back of the driver's side of the trailer, where the winch controls were located, and began to tighten the cable. It was dark, the pavement was dry, and there was no precipitation. The tow truck vehicle warning lights were engaged and functioning but there were no hazard signs or flags on the roadway adjacent to the rollback.

Meanwhile, a box truck driver (owner-operator) was traveling to an auction approximately $61 / 2$ hours away from his origin. The route would take him through three states to his final destination. The vehicle was a 2008 white, single cab truck with a gross vehicle weight of 12,500 pounds. The cargo space was empty. Approximately 1 hour into the journey, around 3:00 a.m., the driver was pulled over by a state trooper and issued a citation for speeding. After receiving the speeding ticket, the driver of the box truck resumed his route and soon crossed the state line into Kentucky.

About one hour later, the box truck approached the mile marker where the tow truck driver was snugging up the winch on his load. As the box truck driver approached the parked tow truck he veered right, crossing the solid white line onto the shoulder. The front right side of the box truck struck the rollback section of the parked towing vehicle where the tow truck operator was standing and where the winch controls were located.

The force of the impact against the tow truck sent the box truck careening back onto the interstate in a northward trajectory before flipping onto its side and skidding to a halt some 38 yards away from the tow vehicle. Inside the damaged box truck, the driver remained conscious. The doors in the cab were lodged shut; the driver traversed the back of the cab and the empty cargo space to the exit in the rear of the vehicle.

The impact killed the tow truck operator instantly; both tow truck passengers were physically unharmed. Moments after impact, the 18-year-old passenger crawled across his younger brother to the driver's side of the cab, retrieved the phone and called 911.

When responders arrived at the scene, they contacted the county coroner who arrived and declared the tow truck driver dead at the scene. After assessing the situation, a field sobriety test was administered to the driver of the box truck resulting in several failed attempts. Subsequently, the officers asked the driver to voluntarily take a breath alcohol test, which he refused. The box truck driver was transported to the hospital for evaluation and the officers on scene requested a warrant to administer the test. Upon receiving the warrant the driver registered a .115 BAC. The time between the request for the warrant and the administration of the breath alcohol test was no more than three hours, according to officials. The box truck driver was charged with homicide in the death of the tow truck operator. 


\section{Cause of Death}

The cause of death was due to massive head and chest injuries resulting from being struck by a motor vehicle.

\section{Recommendations and Discussions}

\section{Recommendation No. 1: Four points of securement should be used when transporting a} load.

Four points of securement should be used when transporting a motor vehicle. The truck only had three points of securement. The four points are located on each corner of the two truck bed and should be properly fastened to the tires on all four corners of the vehicle. Using less than four points of securement may cause the load to shift back and forth and feel unstable. Additionally, not using all four securement sites can put added stress on the remaining ones, causing them to become stretched.

\section{Recommendation No. 2: Towing operators should receive refresher safety and operational} training annually.

Many regulations are in existence regarding safety procedures for the tow truck industry, however there are currently no requirements for training before receiving a tow truck operator's license. It is unknown how much training the tow truck operator had prior to the time of the incident. Completing refresher safety and operational training every year could prevent lives from being lost due to workers being unaware of safety regulations.

\section{Recommendation No. 3: The maximum carrying capacity of a tow truck should not be exceeded.}

The securement sites on the tow truck were stretched beyond their original shape, suggesting the truck had carried loads beyond its maximum capacity. The excess weight of a load can cause a securement site to become warped and misshapen. This could have caused the load to shift back and forth while on the bed of the tow truck, causing it to feel unstable.

\section{Recommendation No. 4: Portable warning devices should be used when outside of the truck to alert approaching motorists.}

Even though it is not required, it is strongly recommended that safety warning devices are deployed anytime that someone is working outside of the tow truck on the side of a road or highway. The device should be displayed throughout the entire time the truck or load is being attended to. Devices with flashers or reflective stripes should be used at night time so that drivers can clearly see them. A simple device like this may have prevented the tragedy involved in this incident. 


\section{Recommendation No. 5: Appropriate high-visibility vests should be worn by persons working along highways and streets.}

The U.S. Department of Transportation's (DOT) Manual on Uniform Traffic Control Devices (MUTCD) states that all workers exposed to the risks of moving roadway traffic or construction equipment should wear high-visibility safety apparel. An ANSI Class II vest is required, however it is strongly recommended that an ANSI Class III vest be used whenever possible. A Class III vest has more coverage and offers the greatest level of visibility.

\section{Recommendation No. 6: There should be increased public awareness of the "Move Over Law" in Kentucky.}

Kentucky's Move Over Law was enacted in July 2000 and revised in June 2003. It is a law designed to protect police officers and other emergency workers stopped alongside the highway. The law requires motorists to approach with caution when an emergency vehicle is stopped with its lights flashing. Motorists must change lanes away from the emergency vehicle if they are traveling on a multi-lane highway and can do so safely. If drivers can't change lanes safely or are traveling on a two-lane highway, they must slow down while maintaining a safe speed so as not to impede other traffic. The Kentucky Transportation Cabinet installed approximately 100 "Move Over or Slow Down" signs throughout the state in 2005. It is recommended that the Kentucky Transportation Cabinet continue to promote awareness of the law through public service announcements and billboards.

\section{Recommendation No. 7: A proper pre-trip and post-trip inspection should be performed at the beginning and closing of each day.}

A Pre-Trip and Post-Trip inspection should always be thoroughly performed to ensure that there are no issues with any of the components of the truck. Doing this routine inspection will help prevent instances in which the driver would have to pull over to the side of the road for mechanical issues. The dual wench controls should be thoroughly checked as a part of this inspection so that they are both in good working condition. This will make it less likely that the driver should have to use the control that is closest to approaching traffic in the event that they are on the roadside.

\section{Recommendation No. 8: Whenever possible, the tow truck driver should pull over at a 'safe' location that allows the truck to be out of the way of approaching traffic.}

Pulling over on the side of a busy road or highway should only be done as a last resort. Ideally, a tow truck driver should pull his unit off to a rest area, turnout, or even to the nearest exit where they can establish a work area with a safer distance from approaching traffic. Most gas stations and restaurants will have adequate space for a tow truck driver to pull over and check on their load. Pulling over to a safe location before exiting the cab of the truck would likely have prevented this tragedy. 
Keywords: Tow truck, load securement, box truck, shoulder.

\section{References}

Federal Motor Carrier Safety Regulations 49 CFR 392 - 399

Society of Automotive Engineers International Standard J684

www.fws.gov/policy/243fw5.html

http://www.fhwa.dot.gov/

http://safety.fhwa.dot.gov/geometric/pubs/mitigationstrategies/chapter3/3_shoulderwidth.htm

http://statutes.laws.com/maryland/transportation/title-22/subtitle-4/22-408

http://mutcd.fhwa.dot.gov/pdfs/2009r1r2/pdf_index.htm

http://www.kentuckystatepolice.org/2004/pr10_04_04.htm

http://migration.kentucky.gov/Newsroom/kve/070205a.htm

\section{Acknowledgements}

The Kentucky FACE Program would like to thank two towing companies and Commercial Vehicle Enforcement.

The Kentucky Fatality Assessment \& Control Evaluation Program (FACE) is funded by grant 2U60OH008483-09 from the Centers for Disease Control and the National Institute for Occupational Safety and Health. The purpose of FACE is to aid in the research and prevention of occupational fatalities by evaluating events leading to, during, and after a work related fatality. Recommendations are made to help employers and employees have a safer work environment. For more information about FACE and KIPRC, please visit our website at: www.kiprc.uky.edu 


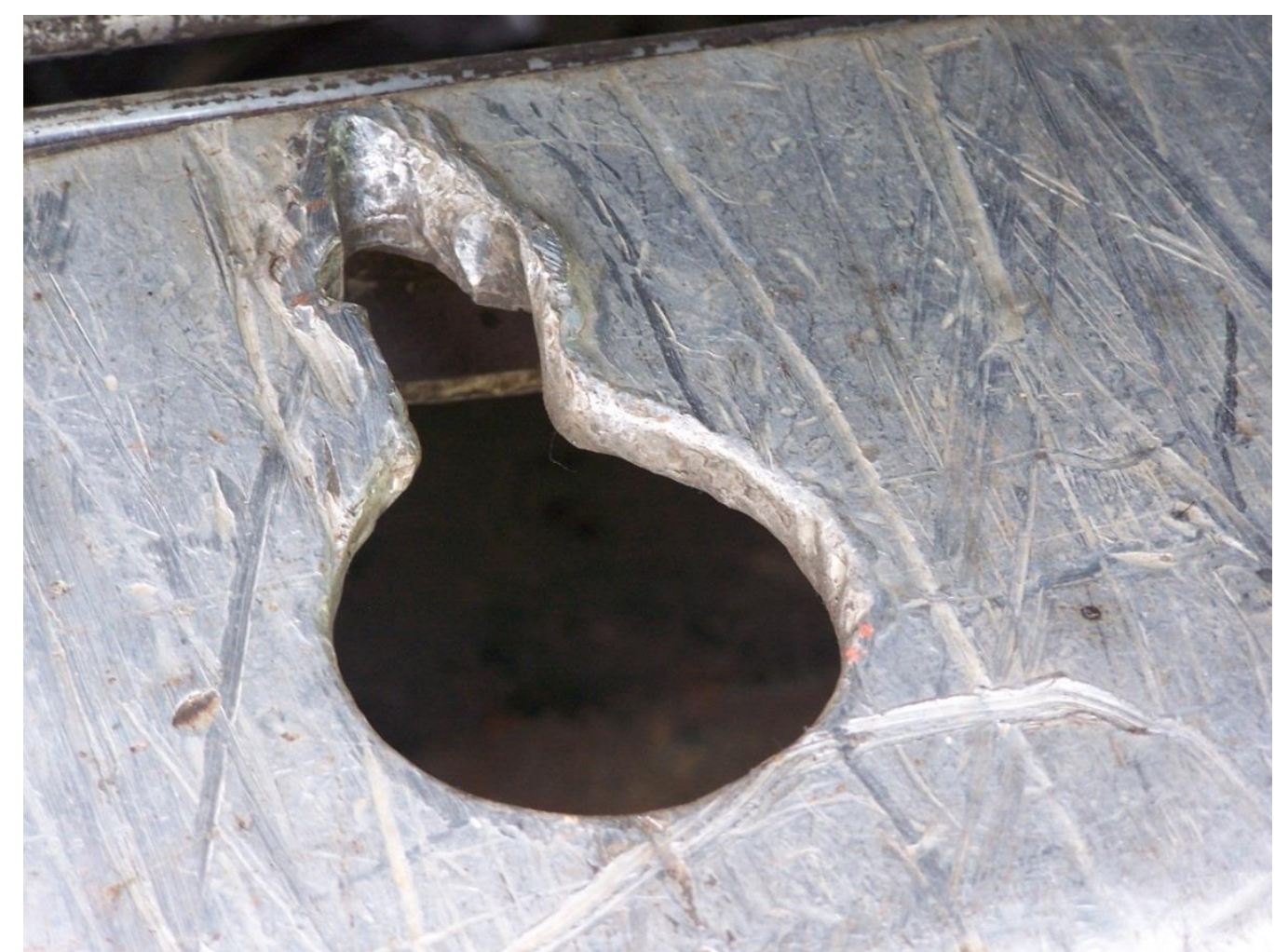

A worn securement site on the tow truck.

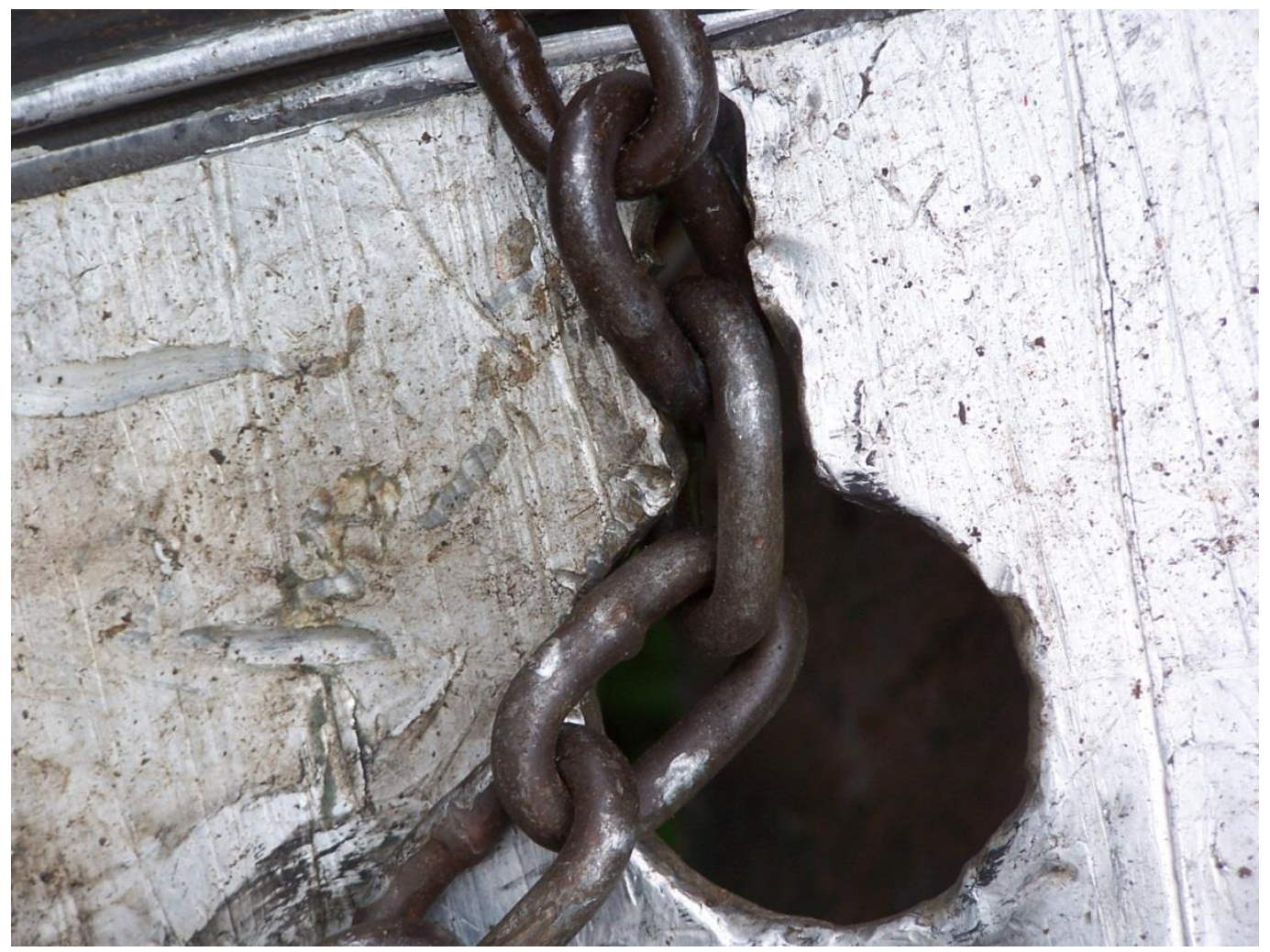

A worn securement site with chain on the tow truck. 


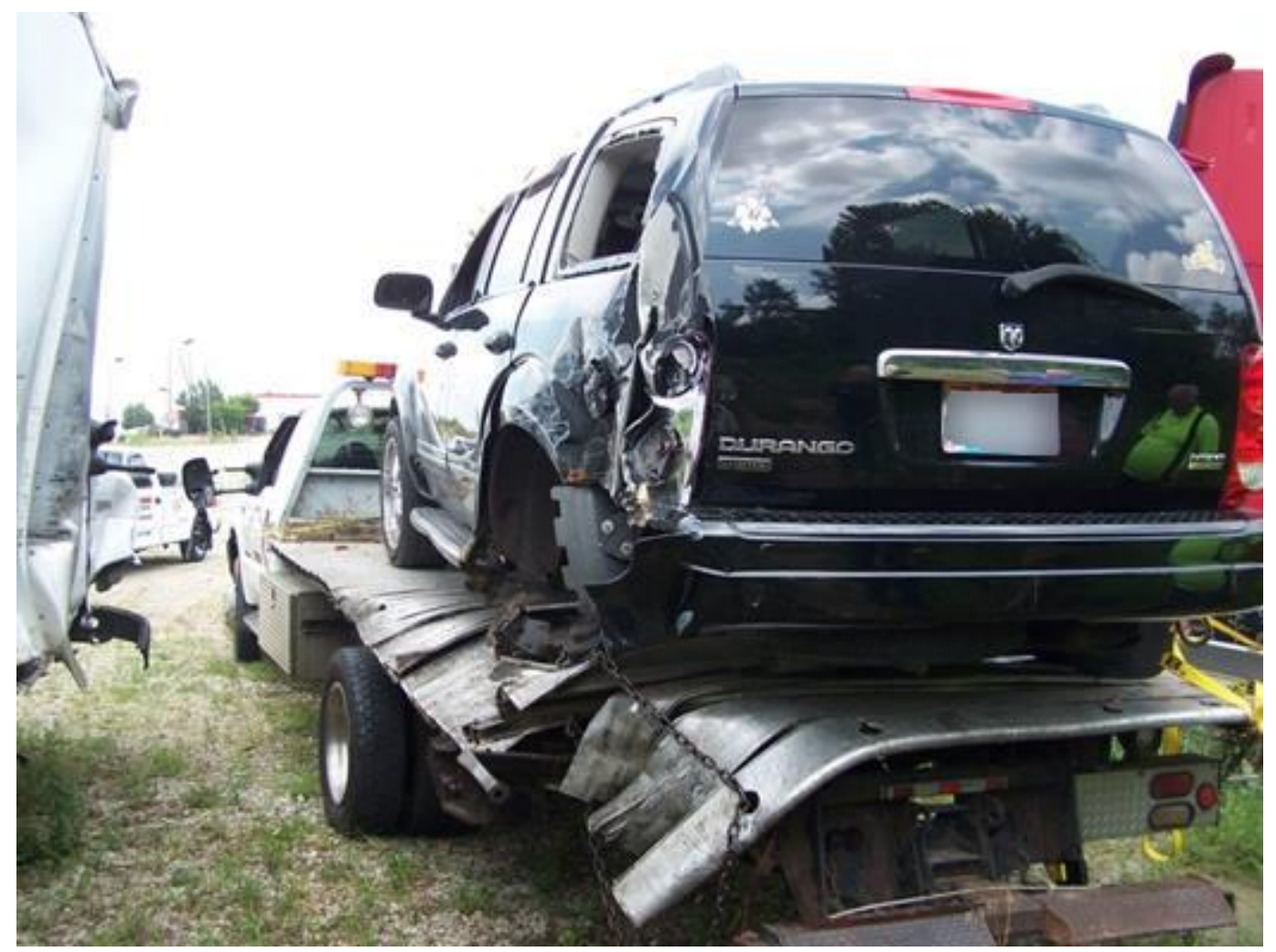

The tow truck with SUV.

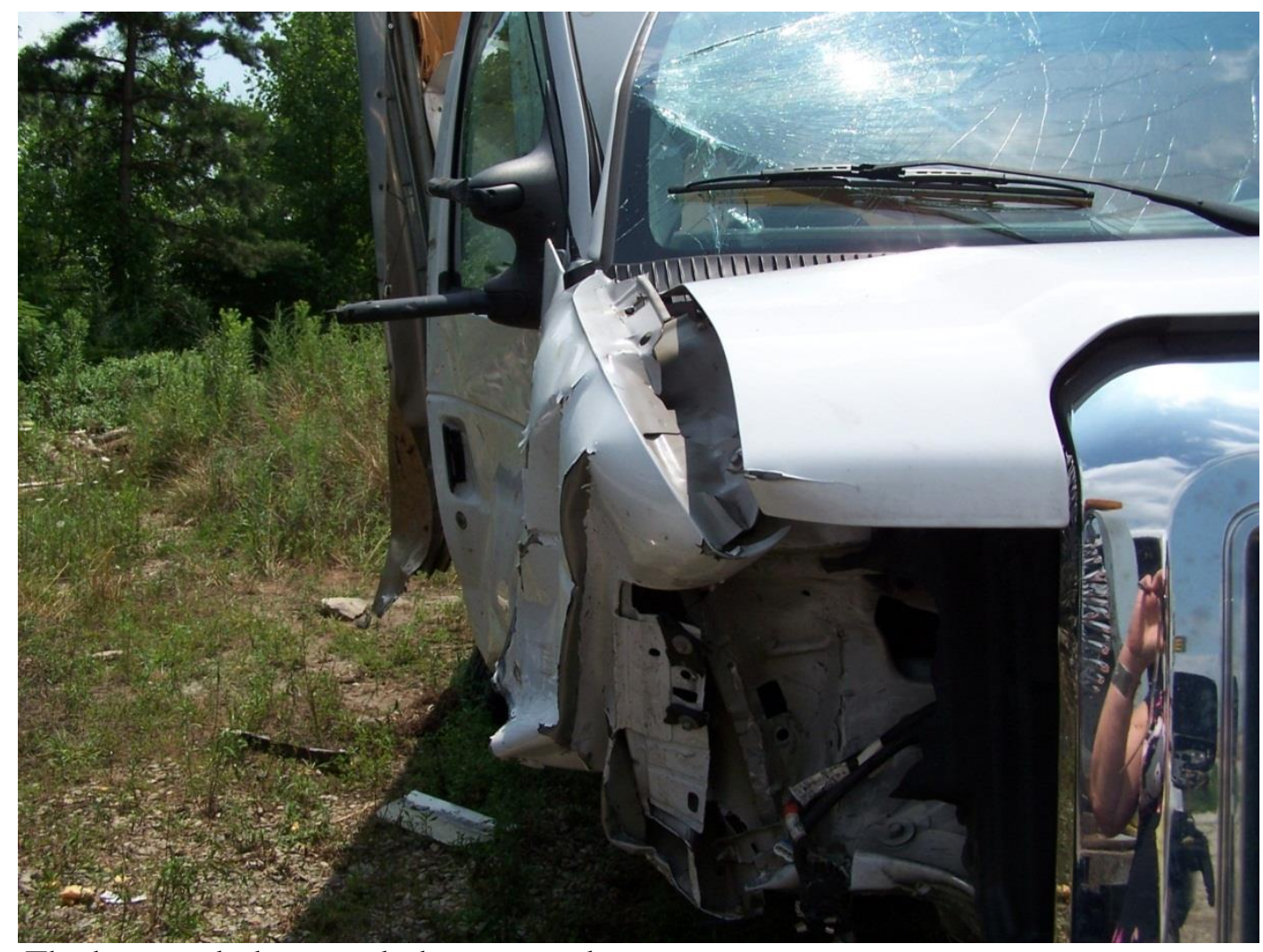

The box truck that struck the tow truck. 


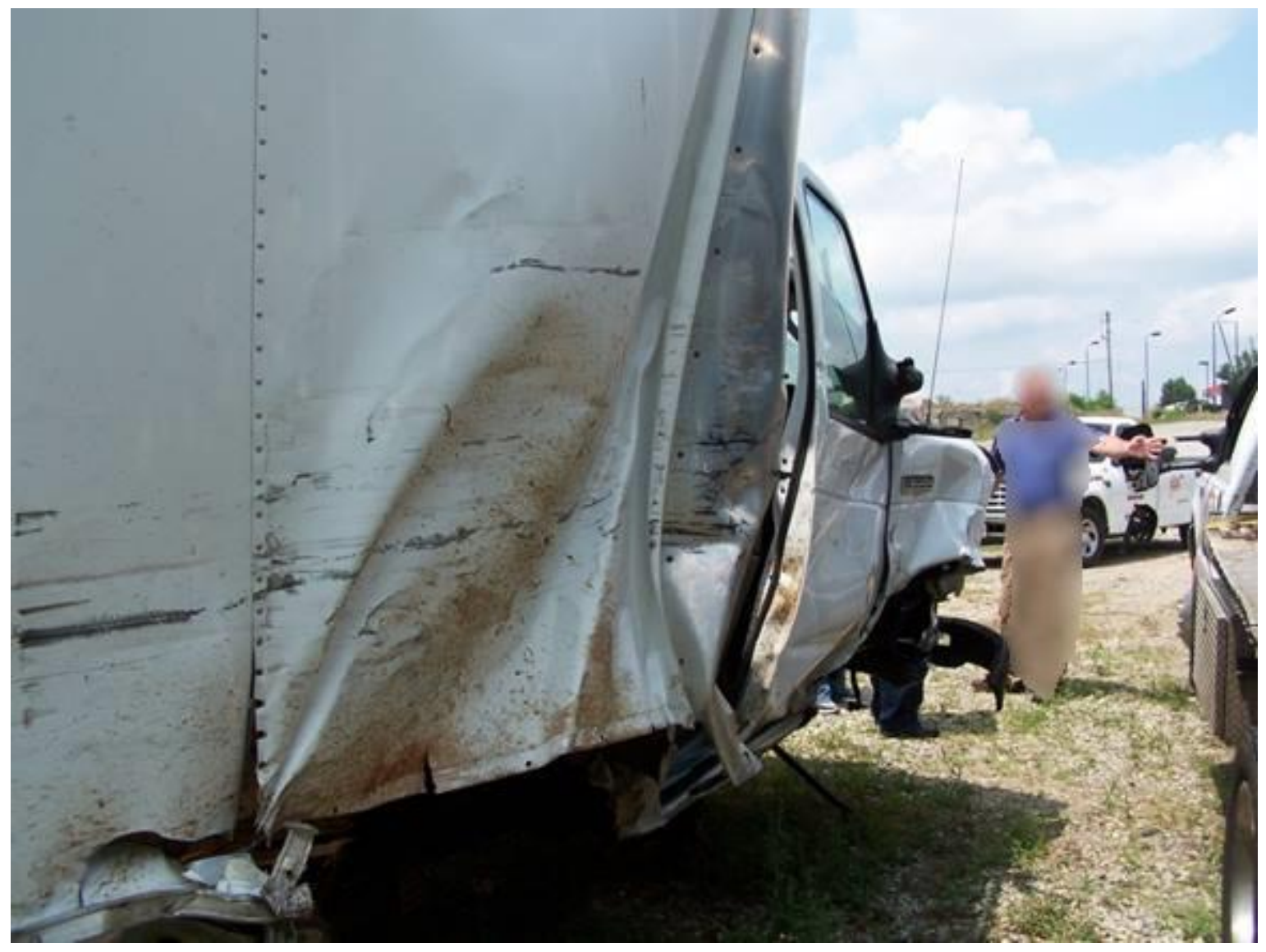

The box truck that struck the tow truck. 